\title{
Performance of a vector control for DFIG driven by wind turbine: real time simulation using DS1104 controller board
}

\author{
Sara Mensou ${ }^{1}$, Ahmed Essadki ${ }^{2}$ Issam Minka ${ }^{3}$, Tamou Nasser ${ }^{4}$, Badre Bououlid Idrissi ${ }^{5}$, \\ Lahssan Ben Tarla ${ }^{6}$ \\ 1, 2, 3 Electrical Engineering Department of ENSET Mohammed V University Rabat, Morocco \\ ${ }^{4}$ Department Communication Networks Department of ENSIAS Mohammed V University Rabat, Morocco \\ ${ }^{5,6}$ Electromechanical Engineering Department of ENSAM Moulay Ismaïl University Meknès, Morocco
}

\begin{tabular}{l} 
Article Info \\
\hline Article history: \\
Received Oct 7, 2018 \\
Revised Feb 14, 2019 \\
Accepted Mar 1, 2019 \\
\hline Keywords: \\
DFIG \\
dSPACE card \\
Indirect field oriented control \\
MPPT method \\
Pulse with modulation \\
Wind turbine
\end{tabular}

\begin{abstract}
In this research paper we investigate the modelling and control of a doubly fed induction generator (DFIG) driven in rotation by wind turbine, the control objectives is to optimize capture wind, extract the maximum of the power generated to the grid using MPPT algorithm (Maximum Power Point Tracking) and have a specified reactive power generated whatever wind speed variable, the indirect field oriented control IFOC with the PI correctors was used to achieve such as decoupled control. To validate the dynamique performance of our controller the whole system was simulated using dSPACE DS1104 Controller board Real Time Interface (RTI) which runs in Simulink/MATLAB software and ControlDesk 4.2 graphical interfaces.
\end{abstract}

Copyright (C) 2019 Institute of Advanced Engineering and Science. All rights reserved.

\section{Corresponding Author:}

Mensou Sara,

Department of Electrical Engineering,

ENSET Mohammed V University Rabat, Morocco.

Email: sara.mensou11@gmail.com

\section{INTRODUCTION}

In recent years, the world has known a rapid evolution in various sectors that means the increase in demand on electrical energy; The uses of traditional fossil and nuclear energy resources pollute the environment, for this reasons countries are focused on development and exploitation of renewable energy sources such as biomasses, wind energy and solar energy which can offer the opportunity to produce the electrical energy in a clean way and help to save the environment [1]. Wind energy is one of the most effective and clean resource, it presents a promising and important source of energy with low cost, so many researchers have been focused on wind energy systems to develop new technologies in order to optimize the capture wind and the electrical power produced [2,4].

In wind farms the most installed generator is the Doubly-Fed Induction Generator DFIG, This machine presents several advantages; it makes possible to better use the wind energy resources by offering a large range variation of speed about $\pm 30 \%$ around the synchronous speed (hyper-synchronous and hyposynchronous mode) [4]. The power converters connected to the rotor are dimensioned to pass a fraction of the nominal power produced by the generator $(20 \%-30 \%)$, consequently, the reduction of losses in power electronics converters and cost compared to others generators [3-6]. To optimize the performance and effectiveness of the aero-generators and extract the maximum of the power generated to the network, several solutions and control technologies have been studied in the literature [3-7]. 
The objectives of this research paper is to extract the maximum of the electrical power generated from the wind turbine for each wind speed variation and validate the dynamic performances of the system by simulation using DS1104 Controller Card which runs in Simulink/MATLAB environment and ControlDesk graphical interface. To control the generator we have used the PI controller for his easy maintenance, good reliability and simplicity of implementation compared to other nonlinear controllers [3-4].

In this paper we start by the modeling of the wind energy conversion system; the modeling of the wind turbine and the DFIG in the Park reference $d-q$, in the second section we present the indirect field oriented control IFOC with the PI corrector to control the rotor side converter (RSC), then we present how to extract the maximum of the power using the MPPT algorithm (Maximum Power Point Tracking), in the fourth section the real time simulation results of the system using DS1104 card was presented, finally a conclusions are given.

\section{MODELING OF WIND ENERGY SYSTEM}

The structure studied in this paper is based on the wind energy conversion system based on a doubly fed induction generator with gearbox; the stator of the machine is connected directly to the network, while the rotor is connected to the grid via two powers converters Figure 1.

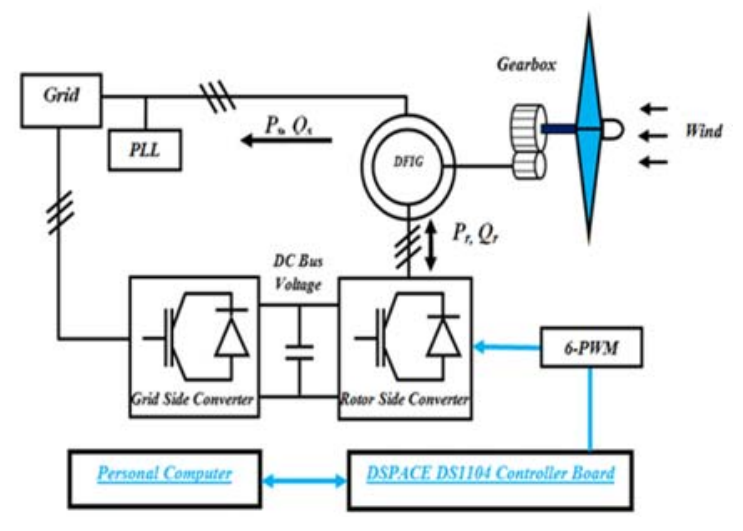

Figure 1. The wind energy conversion system based on a DFIG

\subsection{Wind turbine model}

The modeling of the wind energy system is given by the following [6-7]:

$$
\left\{\begin{array}{l}
P_{v}=\frac{\rho S v^{3}}{2} \\
P_{a e r}=\frac{C_{p}(\lambda, \beta) \rho \cdot S \cdot v^{3}}{2} \\
T_{a e r}=\frac{P_{a e r}}{\Omega_{t}}=\frac{C_{p}(\lambda, \beta) \rho \cdot S \cdot v^{3}}{2 \Omega_{t}}
\end{array}\right.
$$

The power coefficient $\mathrm{Cp}$ depending on the blade pitch angle $\beta$ and the Tip Speed Ratio (TSR) $\lambda$ are defined as follows [7]:

$$
\left\{\begin{array}{l}
C_{p}(\lambda, \beta)=0.5176\left(\frac{116}{\lambda_{i}}-0.4 \beta-5\right) e^{-\frac{21}{\lambda_{i}}}+0.0068 \lambda \\
\lambda_{i}=\frac{1}{\lambda+0.008 \beta}-\frac{0.035}{\beta^{3}+1} \\
\lambda=\frac{\Omega_{t} R}{v}
\end{array}\right.
$$


Where $P_{v}, P_{\text {aer }}, \rho, S, R, \Omega_{t}$ and $v$ are the power of the wind turbine, the aerodynamic power available on the rotor, the aerodynamic torque, the air density $(\rho=1.22 \mathrm{~kg} / \mathrm{m} 3)$, the circular surface swept by the turbine, the radius of the turbine, the turbine tpeed $(\mathrm{rad} / \mathrm{s})$ and the wind speed $(\mathrm{m} / \mathrm{s})$, respectively. The fundamental equation of dynamics is given by [8-9]:

$$
J \frac{d \Omega_{m e c}}{d t}=T_{g}-T_{e m}-C_{f} \Omega_{m e c}
$$

Where $\Omega_{m e c}, J, T_{g}, T_{e m}$ and $\mathrm{C}_{\mathrm{f}}$ are the mechanical rotor speed ( $\left.\mathrm{rad} / \mathrm{s}\right)$, the total inertia, the generator torque, the electromagnetic torque and the coefficient of viscous friction, respectively.

\subsection{Mathematical model of DFIG}

The mathematical model of the stator and rotor voltages of the doubly fed induction generator in the Park reference (d-q) is given by the following [10]:

$$
\begin{aligned}
& \left\{\begin{array}{l}
V_{s d}=R_{s} I_{s d}+\frac{d \phi_{s d}}{d t}-\phi_{s q} \omega_{s} \\
V_{s q}=R_{s} I_{s q}+\frac{d \phi_{s q}}{d t}+\phi_{s d} \omega_{s} \\
V_{r d}=R_{r} I_{r d}+\frac{d \phi_{r d}}{d t}-\phi_{r q} \omega_{r} \\
V_{r q}=R_{r} I_{r q}+\frac{d \phi_{r q}}{d t}+\phi_{r d} \omega_{r}
\end{array}\right. \\
& \left\{\begin{array}{l}
\phi_{s d}=L_{s} I_{s d}+L_{m} I_{r d} \\
\phi_{s q}=L_{s} I_{s q}+L_{m} I_{r q} \\
\phi_{r d}=L_{s} I_{r d}+L_{m} I_{s d} \\
\phi_{r q}=L_{r} I_{r q}+L_{m} I_{s q}
\end{array}\right.
\end{aligned}
$$

Where $\mathrm{L}_{s}, \mathrm{~L}_{\mathrm{r}}$ are the cyclic stator/rotor inductance, $\mathrm{L}_{\mathrm{m}}$ is the maximum of the mutual inductance and $\mathrm{R}_{\mathrm{s}}, \mathrm{R}_{\mathrm{r}}$ are the stator/rotor resistance. The stator active/reactive powers \& the electromagnetic torque of the DFIG are given by [11-12]:

$$
\begin{aligned}
& \left\{\begin{array}{l}
P_{s}=V_{s d} I_{s d}+V_{s q} I_{s q} \\
Q_{s}=V_{s q} I_{s d}-V_{s d} I_{s q}
\end{array}\right. \\
& T_{e m}=\frac{3}{2} p \frac{L_{m}}{L_{s}}\left(\phi_{s q} I_{r d}-\phi_{s d} I_{r q}\right)
\end{aligned}
$$

\subsection{Converter model}

The Rotor Side Converter (RSC) controlled by the Pulse with Modulation (PWM) signals is modelled by a matrix. The matrix that connects the rotor voltages of the DFIG $\left(\mathrm{V}_{\mathrm{ra}}, \mathrm{V}_{\mathrm{rb}}, \mathrm{V}_{\mathrm{rc}}\right)$ and the control signals provided from the PWM module $\left(\mathrm{S}_{\mathrm{a}}, \mathrm{S}_{\mathrm{b}}, \mathrm{S}_{\mathrm{c}}\right)$ is constructed as follow [3]:

$$
\left[\begin{array}{l}
V_{r a} \\
V_{r b} \\
V_{r c}
\end{array}\right]=\frac{U_{d c}}{3}\left[\begin{array}{ccc}
2 & -1 & -1 \\
-1 & 2 & -1 \\
-1 & -1 & 2
\end{array}\right]\left[\begin{array}{l}
S_{a} \\
S_{b} \\
S_{c}
\end{array}\right]
$$

Where: $U_{d c}$ is the DC link Voltage.

Performance of a vector control for DFIG driven by wind turbine: real time simulation ... (Sara Mensou) 


\section{CONTROLLERS MODEL}

\subsection{Indirect field oriented control (IFOC)}

To control the reactive power and the Torque of the generator (DFIG) independently we have to apply the vector control in order to ensure a decoupling between the variables of the machine [13]. In this paper, we chose a two phases d-q linked to the rotating reference frame, and the stator flux is oriented along the axis d, the expression of the flux becomes [14]:

$$
\left\{\begin{array}{l}
\phi_{s d}=\phi_{s} \\
\phi_{s q}=0
\end{array}\right.
$$

Assuming that the flux stator is oriented along the axis $\mathrm{d}$ and constant at the permanent regime and the stator resistance $R_{s}$ of the generator is neglected, the equations of the stator and rotor voltages can be expressed as [14-15]:

$$
\begin{aligned}
& \left\{\begin{array}{l}
V_{s d}=R_{s} I_{s d}+\frac{d \phi_{s d}}{d t}-\phi_{s q} \omega_{s}=0 \\
V_{s q}=R_{s} I_{s q}+\frac{d \phi_{s q}}{d t}+\phi_{s d} \omega_{s}=\phi_{s} \omega_{s}
\end{array}\right. \\
& \left\{\begin{array}{l}
V_{r d}=R_{r} I_{r d}+\left(L_{r}-\frac{L_{m}{ }^{2}}{L_{s}}\right) \frac{d I_{r d}}{d t}-\omega_{r}\left(L_{r}-\frac{L_{m}{ }^{2}}{L_{s}}\right) I_{r q} \\
V_{r q}=R_{r} I_{r q}+\left(L_{r}-\frac{L_{m}{ }^{2}}{L_{s}}\right) \frac{d I_{r q}}{d t}+\omega_{r}\left(L_{r}-\frac{L_{m}{ }^{2}}{L_{s}}\right) I_{r d}+\omega_{r} \frac{L_{m}}{L_{s}} \phi_{s}
\end{array}\right.
\end{aligned}
$$

The expressions for the stator powers \& the electromagnetic torque of the DFIG are given by [16]:

$$
\begin{aligned}
& \left\{\begin{array}{l}
P_{s}=-\frac{V_{s} L_{m}}{L_{s}} I_{r q} \\
Q_{s}=\frac{V_{s} \phi_{s}}{L_{s}}-\frac{V_{s} L_{m}}{L_{s}} I_{r d}
\end{array}\right. \\
& T_{e m}=-\frac{3}{2} p \frac{L_{m}}{L_{s}} \phi_{s} I_{r q}
\end{aligned}
$$

Fundamentally, the indirect field oriented method using the proportional integral correctors consists of two control loops [2]. The first loop serves to calculate reference rotor currents $\left(\mathrm{I}_{\mathrm{rq}} * \mathrm{I}_{\mathrm{rd}} *\right)$, this control loop gets its reference from the maximum power point tracking algorithm (MPPT) in order to optimize the power produced from the generator for each wind speed changes. The second loop is used to determine the rotor voltages references $\left(\mathrm{V}_{\mathrm{rq}} *, \mathrm{~V}_{\mathrm{rd}} *\right.$ ). According to (11), (12) and (13) we concluded that $\mathrm{V}_{\mathrm{rd}} *$ and $\mathrm{V}_{\mathrm{rq}} *$ are the variables of the rotor voltages to impose on the DFIG to get the rotor currents, the electromagnetic torque and the reactive stator power desired. The proposed model is given in Figure 2. 


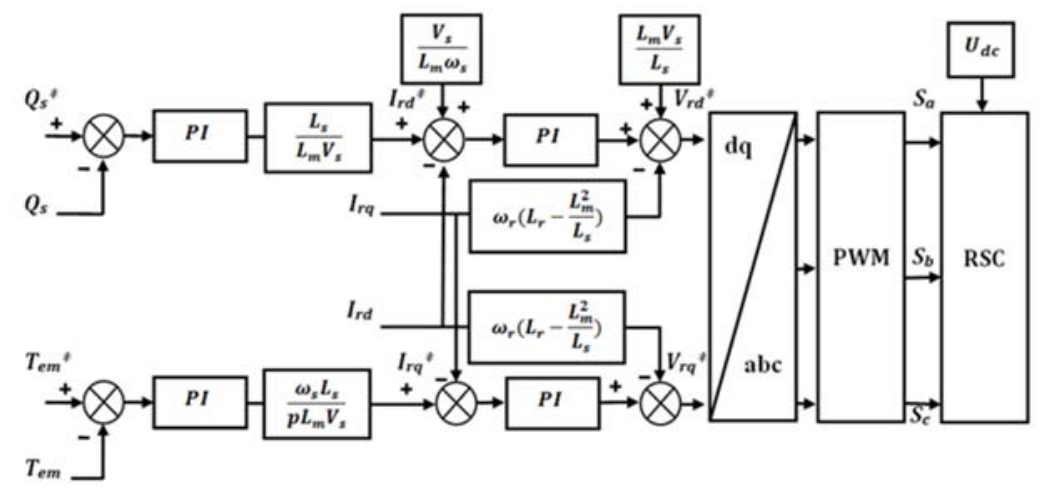

Figure 2. The proposed model using the PI controller

\subsection{Proportional integral (PI) controller design}

The synthesis of the proportional integral (PI) regulators is divided into two steps; the first step serves to regulate the currents and the second step to regulate the powers/torque. The rotor current loop is shown in Figure 3.

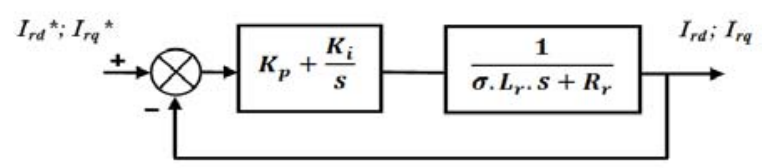

Figure 3. Rotor current control loop

Where: $\sigma=1-\frac{L_{m}^{2}}{L_{s} \cdot L_{r}}$

The Open Loop Transfer Function H(p) is given by:

$$
\mathrm{H}(p)=\left(k_{p}+\frac{k_{i}}{s}\right)\left(\frac{1}{\sigma L_{r} s+R_{r}}\right)=\left(\frac{s k_{p} / k_{i}+1}{s / k_{i}}\right)\left(\frac{1 / R_{i}}{s \sigma L_{r} / R_{i}+1}\right)
$$

The compensation method is used to eliminate the zero of the transfer function $H(p)$, to ensure the performance of the compensation method the parameters of the transfer function most be known, we choose:

$$
\frac{k_{p}}{k_{i}}=\frac{\sigma L_{r}}{R_{r}}
$$

The Open Loop Transfer Function H(p) becomes:

$$
\mathrm{H}(p)=\frac{k_{i}}{s R_{r}}
$$

The Closed Loop Transfer Function G(p) is giving by the following equation:

$$
G(p)=\frac{k_{i} / s R_{r}}{1+k_{i} / s R_{r}}=\frac{1}{1+s \tau_{i}}
$$


Where $\tau_{i}=\frac{R_{r}}{k_{i}}$; for the rotor current control loop we set the response time $\tau_{\mathrm{i}}=1 \mathrm{~ms}$ in order to have a good tracking. Finally, we get: $k_{i}=\frac{R_{r}}{\tau_{i}}$ and $k_{p}=\frac{\sigma L_{r}}{\tau_{i}}$. We used the same steps to calculate the gain of the power/torque correctors. We get: $k_{i i}=\frac{1}{\tau_{i}}$ and $k_{p p}=\frac{R_{r}}{\tau_{i} k_{i}}$.

\subsection{Maximum power point tracking (MPPT Control)}

To extract the maximum power generated it is necessary to provide the adequate electromagnetic torque which is used to vary the mechanical rotor speed of the DFIG for each wind speed variation [6]. In order to estimate the value of the wind speed which gives the maximum of the power we can fixed the TSR to its optimum value $\lambda_{\text {opt }}$ that corresponds to the maximum power coefficient $\mathrm{C}_{\mathrm{p} \text {-max }}$, According to (1) and (2) it's can be possible to deduce the expression of the reference electromagnetic torque as a function of the optimum TSR $\lambda_{\text {opt }}$ and mechanical rotor speed $\Omega \operatorname{mec}[3-6]$ :

$$
T_{\text {em ref }}=\frac{1}{2} C_{p \max }(\lambda, \beta) \frac{\rho \cdot \pi \cdot R^{5}}{\left(G \cdot \lambda_{\text {opt }}\right)^{3}} \Omega_{m e c}^{2}
$$

Where $G$ is the gain of the multiplier wich adjusts the turbine speed to the rotor speed of DFIG. The block diagram in Figure 4 presents the model of the turbine and the MPPT Algorithm.

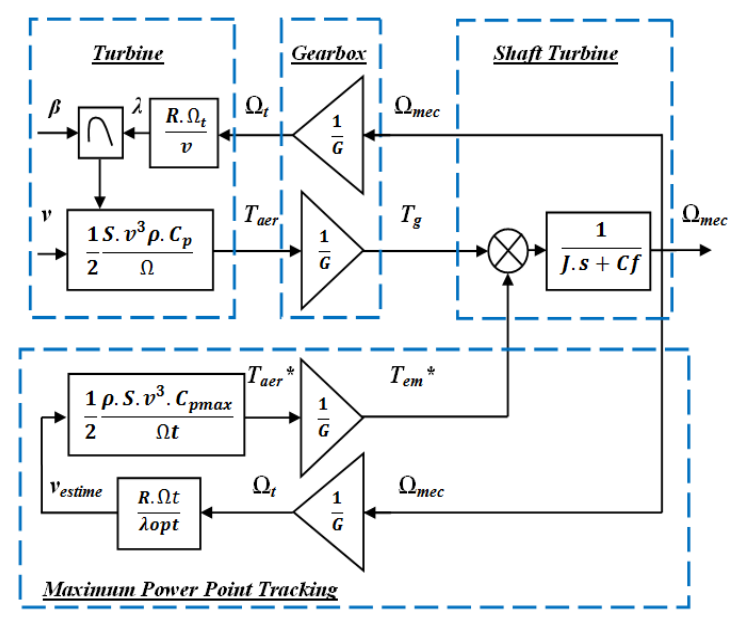

Figure 4. Block diagram of the MPPT Method

\section{DSPACE DS1104 CONTROLLER BOARD}

The dSPACE DS1104 Controller card is a cost effective system with a real time processor, it can be mounted in a personal computer with a 5V PCI slot. The function models are easily turned on the DS1104 system with Real Time Interface (RTI), to configure the Input \& Output of the system studied graphically the ControlDesk interface can be used, insert the blocks diagrams and generate the model code via SIMULINK software; the real time simulated models are compiled, downloaded, and started automatically [17]. This increases systematically the productivity and reduces development costs and times. Figure 5 shows the block diagram of the DS1104 Controller Card used in our laboratory which consists of a main processor PowerPC 64-bit floating point processor with a CPU Clock $250 \mathrm{MHz}$, a slave DSP I/O and a master PPC I/O subsystem [17-18]. Figure 6 presents the model of the Control System under DS1104 RTI1104 which runs in SIMULINK.

Int J Pow Elec \& Dri Syst, Vol. 10, No. 2, June 2019: 1003 - 1013 


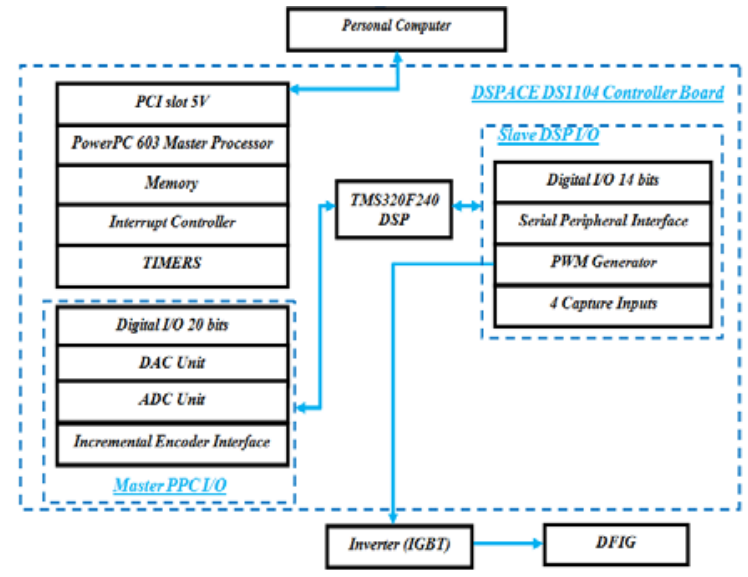

Figure 5. Block diagram of the DS1104 Controller Card

The dSPACE board used consists of three components:

a. DS1104 Controller Card installed in the PC

b. Panel for connecting signal lines to the DS1104.

c. Software tools for operating the card through the SIMULINK block diagram environment

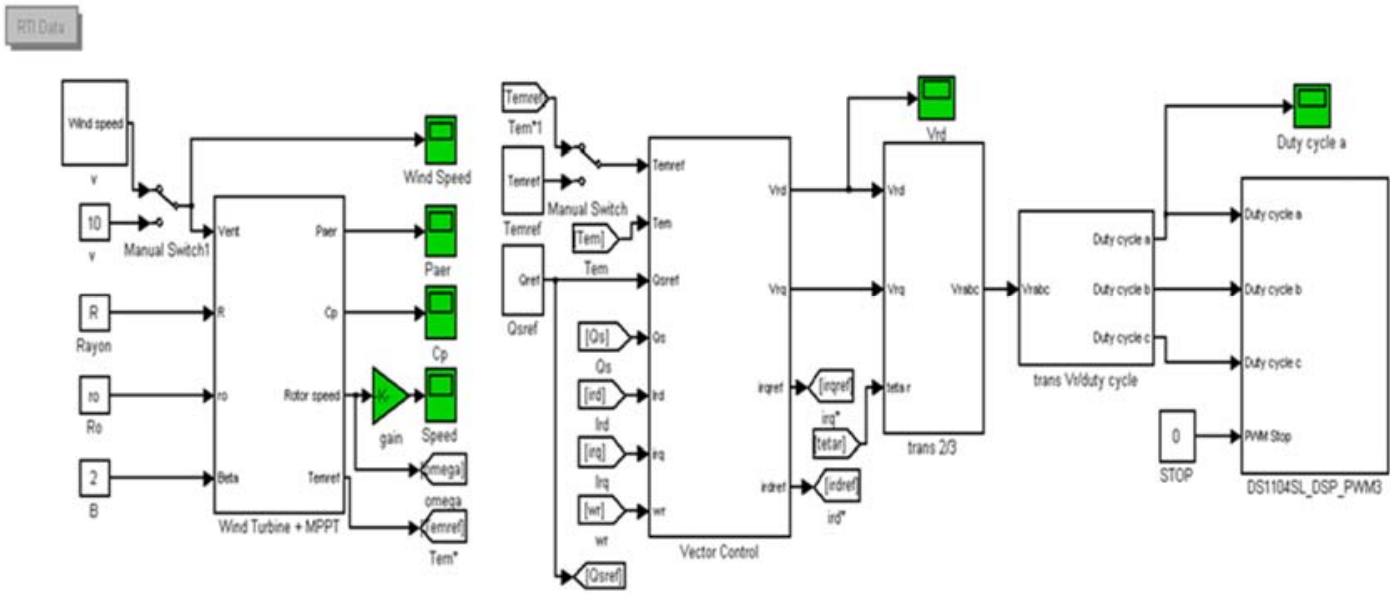

Figure 6. Control System simulated under dSPACE DS1104 RTI

\section{RESULTS AND DISCUSSIONS}

The simulation of the whole system is performed using the Simulink/MATLAB software. The Table 1 resumes the parameters of the wound induction generator A4222 $(1.5 \mathrm{~kW})$, after doing the experimental determination of the parameters in our Laboratory.

Table 1. Parameters of the Generator A4222

\begin{tabular}{ccccccc}
\hline $\mathrm{R}_{\mathrm{s}}(\Omega)$ & $\mathrm{R}_{\mathrm{r}}(\Omega)$ & $\mathrm{L}_{\mathrm{s}}(\mathrm{H})$ & $\mathrm{L}_{\mathrm{r}}(\mathrm{H})$ & $\mathrm{L}_{\mathrm{m}}(\mathrm{H})$ & $\mathrm{P}_{\mathrm{n}}(\mathrm{kW})$ & $\mathrm{V}_{\mathrm{s}}(\mathrm{V})$ \\
\hline 1.18 & 1.66 & 0.20 & 0.18 & 0.17 & 1.5 & $220 / 380$ \\
\hline
\end{tabular}

\subsection{Simulation results}

To improve the performances of the system we apply a variable wind speed profile, it is modeled by a sum of several harmonics around an average speed of $10.5(\mathrm{~m} / \mathrm{s})$ presented in Figure 7, despite of the variations of the wind speed the power coefficient $C_{p}$ is keeps at its maximum value $C_{p-\max }=0.49$

Performance of a vector control for DFIG driven by wind turbine: real time simulation ... (Sara Mensou) 
(show Figure 8), which ensure the effectiveness of the Maximum Power Point Tracking (MPPT) algorithm. Comparing Figure 9 with Figure 10 we notice that the decoupling between the currents rotor $\mathrm{I}_{\mathrm{rd}}$ and $\mathrm{I}_{\mathrm{rq}}$ is ensured and the tracking response is well done using PI correctors.

Figures 9 and 10 illustrate the reactive stator power $Q_{s}$ and the electromagnetic torque $T_{e m}$, they track perfectly their reference values against wind speed variations, the electromagnetic torque $T_{\mathrm{em}}$ follows exactly the reference $\mathrm{T}_{\mathrm{em}}$ * calculated from the MPPT method, thus a small variation of the wind introduces a great variation on the torque, the reactive power stator $Q_{s}$ shown in Figure 12 is fixed at 0 VAR to have a unity power factor on the stator side and optimize the quality of the electrical energy produced to the grid.

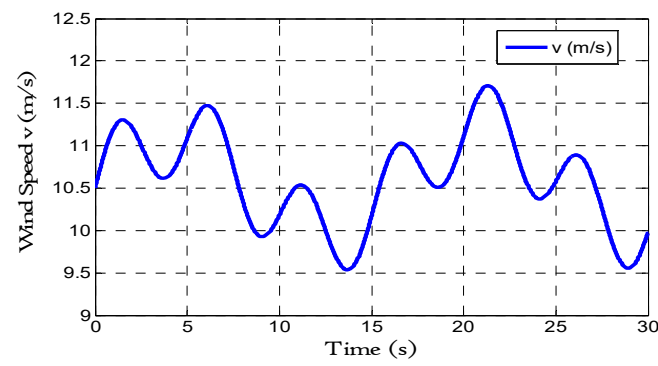

Figure 7. Wind Speed $(\mathrm{m} / \mathrm{s})$

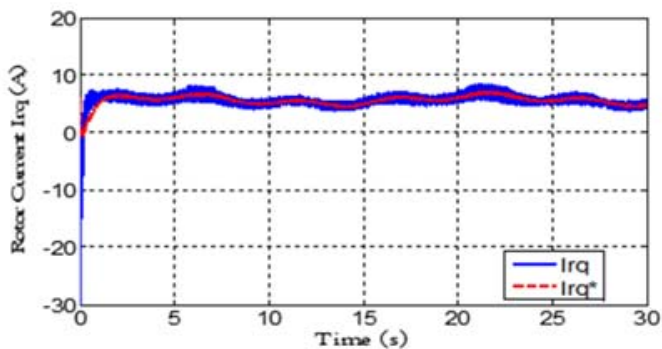

Figure 9. Current Rotor Irq \& Irq* (A)

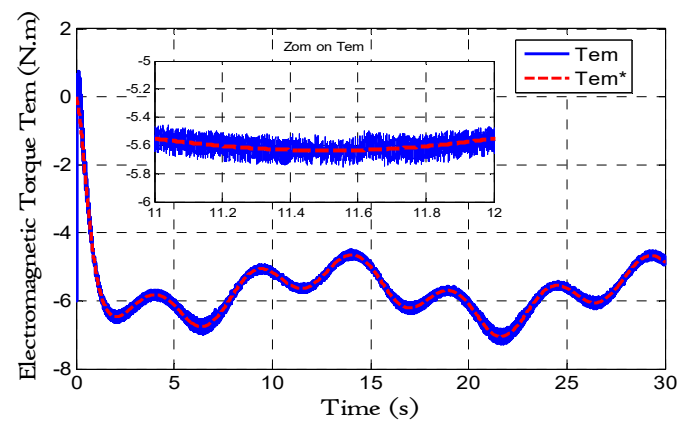

Figure 11. Electromagnetic Torque Tem \& Tem* (N.m).

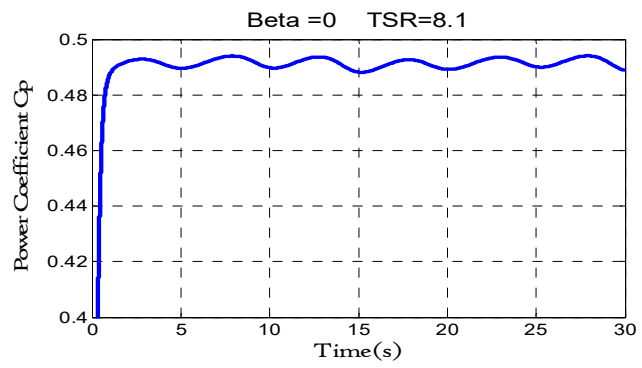

Figure 8. Power Coefficient $\operatorname{Cp}(\lambda, \beta)$

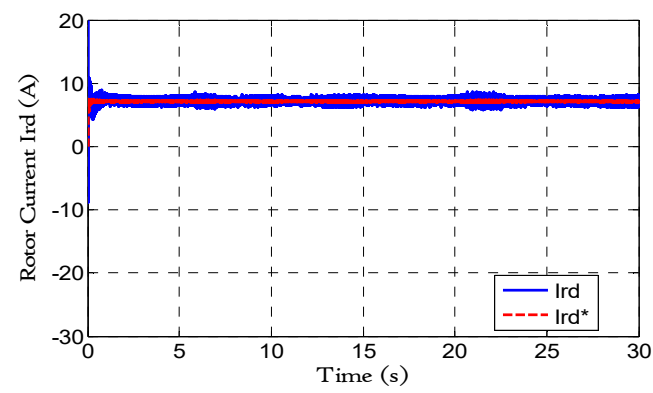

Figure 10. Current Rotor Ird \& Ird* (A).

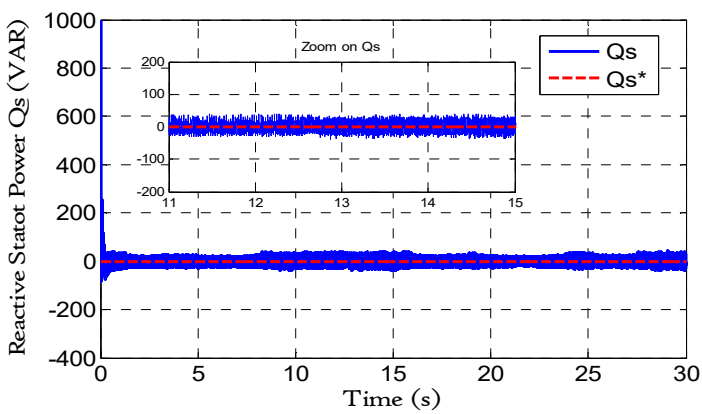

Figure 12. Stator Reactive Power Qs \& Qs* (VAR).

Figure 13 illustrates that the currents stator $I_{s}$ for the three phases are sinusoidal with $\mathrm{f}_{\mathrm{s}=50}(\mathrm{~Hz})$. Figure 14 gives the spectrum analysis of the Total Harmonic Distortion (THD) of the stator current for the phase (a) $I_{\mathrm{sa}}$, as we see $\mathrm{THD}=6.65 \%$, the harmonics appearing on the injected stator current $\mathrm{I}_{\mathrm{sa}}$ to the grid are minimized that implies the wind energy provide the optimal electrical energy to the network. 


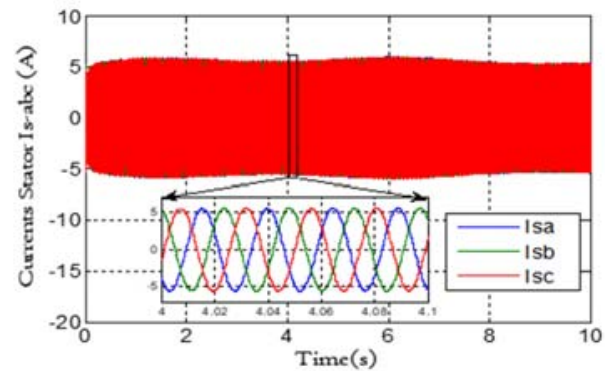

Figure 13. Currents Stator Is-abc (A)

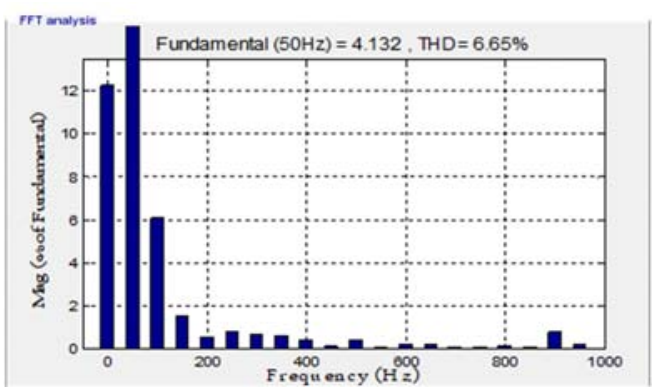

Figure 14. Spectrum analysis of the Total Harmonic Distortion for the Current Stator Isa

\subsection{Hardware co-simulation results}

In this research paper the Real Time Simulation (RTS) of the stator active power $\mathrm{P}_{\mathrm{s}}$, the stator reactive power $\mathrm{Q}_{\mathrm{s}}$, the electromagnetic torque $\mathrm{T}_{\mathrm{em}}$ and current rotor $\mathrm{I}_{\mathrm{rq}}$ was carried out in Simulink/MATLAB environment with dSPACE RTI1104 Real Time Interface (RTI) block set libraries. The results shown on the graphical interface created under ControlDesk 4.2 Figure 15 were satisfactory that confirm the effectiveness and performance of our controllers (Indirect Field Oriented Control (IFOC) and Maximum Power Point Tracking (MPPT) algorithm).

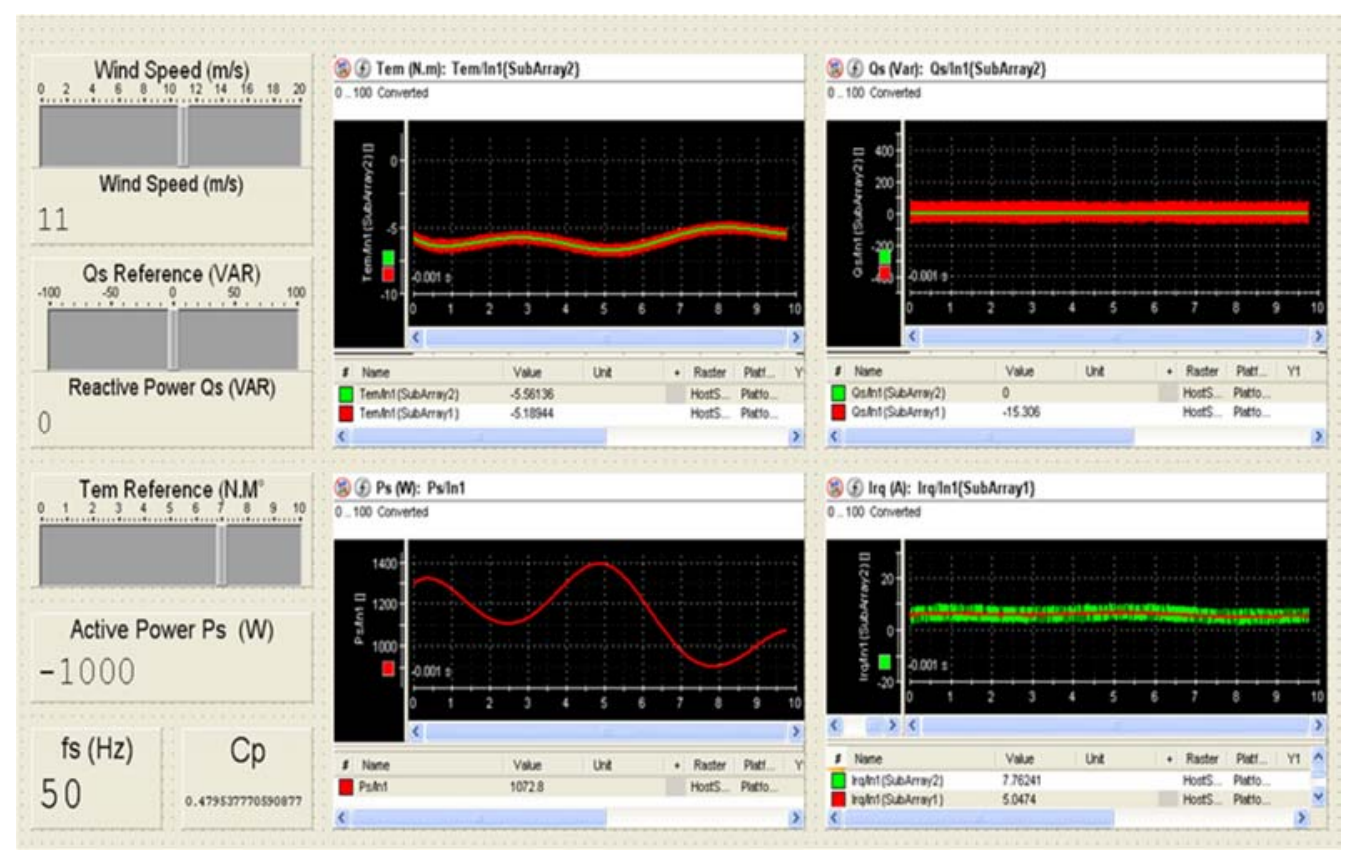

Figure 15. Graphical interface created under ControlDesk

\section{CONCLUSION}

The work was devoted to control a Doubly Fed Induction Generator applied in a wind energy conversion system. After modelling the whole system we have adopted the Indirect Field Oriented Control (IFOC) to control the reactive stator power and the electromagnetic torque independently, then the MPPT Algorithm to extract the maximum of the power generated to the network.

The Wind Power Generation System was modelled and simulated with a variable speed operation for a power of $1.5(\mathrm{~kW})$. To validate the proposed control model we have performed a simulation used dSPACE RTI1104 Real Time Interface. The results obtained under ControlDesk 4.2 graphical interface were satisfactory that ensure the performances of the control system studied.

Performance of a vector control for DFIG driven by wind turbine: real time simulation ... (Sara Mensou) 


\section{ACKNOWLEDGEMENTS}

This work is supported by: ENSET, Mohammed V University Rabat, Morocco. The authors would like to thank all researchers and professors of the Electromechanical Engineering Department of ENSAM Moulay Ismaïl University Meknès, Morocco.

\section{REFERENCES}

[1] B. Beltran, T. Ahmed Ali, M. Benbouzid, "Sliding Mode Power Control of Variable Speed Wind Energy Conversion Systems", IEEE Transl. Energy Conversion, vol. 23, pp. 551-558, June 2008.

[2] N. Bouchiba, A. Barkia, L. Chrifi Alaoui, S. Drid, S. Sallem, \& M. B. A. kammoun, "Real-Time Integration of Control Strategies for an Isolated DFIG -based WECS", The European Physical Journal Plus, Vol. 132, No. 8, pp. 334-344, 2017.

[3] S. Mensou, A. Essadki, T. Nasser, B. B. Idrissi, "An Efficient Nonlinear Backstepping Controller Approach of a Wind Power Generation System Based on a DFIG”. International Journal of Renewable Energy Research, Vol.7, No 4, pp. 1520-1528, December 2017.

[4] M. El Azzaoui, H. Mahmoudi, K. Boudaraia, "Backstepping Control of wind and photovoltaic hybrid Renewable Energy System”.International Journal of Power Electronics and Drive Systems (IJPEDS),Vol.7, pp. 677-686, 2016.

[5] B. Bossoufi, M. Karim, A. Lagrioui, \& all, "Observer Backstepping Control of DFIG-Generators for Wind Turbines Variable Speed: FPGA-Based Implementation”. Renewable Energy, Elsevier, Vol. 81, pp. 903-917, 2015.

[6] R. Chakib, A. Essadki, M. Cherkaoui, "Modeling and Control of a Wind System based on a DFIG by Active Disturbance Rejection Control", International Review on Modeling and Simulations, Vol. 7, pp. 626-637, 2014.

[7] D. R. Robinett III, G. D. Wilson, "Nonlinear Power Flow Control Design: utilizing exergy, entropy, static and dynamic stability, and lyapunov analysis", Springer Science \& Business Media, 2011.

[8] F. Senani, A. Rahab, \& H. Benalla, "A Complete Modeling and Control for Wind Turbine Based of a Doubly Fed Induction Generator using Direct Power Control". International Journal of Power Electronics and Drive Systems (IJPEDS), Vol. 8, No. 4, pp. 1954-1962, 2017.

[9] A. Rahab, F. Senani, \& H. Benalla,"Direct power control of brushless doubly-fed induction generator used in wind energy conversion system”. International Journal of Power Electronics and Drive Systems (IJPEDS), Vol. 8, No. 1, pp. 417-433, 2017.

[10] S. Mensou, A. Essadki, I. Minka, T. Nasser \& B. B. Idrissi, "Backstepping Controller for a Variable Wind Speed Energy Conversion System Based on a DFIG", Proceeding of the 5th International Renewable and Sustainable Energy Conference (IRSEC), December 2017.

[11] N. El Ouanjli, A. Derouich, A. El Ghzizal, Y. El Mourabit, B. Bossoufi \& M. Taoussi, "Contribution to the Performance Improvement of Doubly Fed Induction Machine Functioning in Motor Mode by the DTC Control" International Journal of Power Electronics and Drive Systems (IJPEDS), Vol. 8, No. 3, pp. 1117-1127, September 2017.

[12] I. Minka, A. Essadki, S. Mensou \& T. Nasser "Power Control of a DFIG Driving By Wind Turbine: Comparison Study Between ADRC and PI Controller", Proceeding of the 5th International Renewable and Sustainable Energy Conference (IRSEC), December 2017.

[13] Z. Mekrini, S. Bri, "Performance of an Indirect Field Oriented Control for Asynchronous Machine", International Journal of Engineering and Technology, vol. 8, pp. 726-733, Apr-May 2016.

[14] K. Ghedamsi, E.M. Berkouk, "Control of Wind Generator Associated to a Flywheel Energy Storage System", Renewable Energy, Elsevier, Vol. 33, pp. 2145-2156, 2008.

[15] S. Mensou, A. Essadki, T. Nasser \& B. B. Idrissi, "A Robust Speed Control of a Doubly Fed Induction Generator Using in WECS by the Nonlinear Backstepping Controller". Proceeding of the 3rd International Conference on Electrical and Information Technologies (ICEIT), pp. 1-6, November 2017.

[16] Y. Ihedrane, C. El Bekkali, B. Bossoufi, "Improved Performance of DFIG-generators for Wind Turbines Variablespeed", International Journal of Power Electronics and Drive Systems (IJPEDS), Vol. 9, No. 4, pp. 1875-1890, December 2018.

[17] Z. A. Ghani, M. A. Hannan, \& A. Mohamed, "Renewable Energy Inverter Development Using dSPACE DS1104 Controller Board". Proceeding of the IEEE Conference on Power and Energy, pp. 69-73, November 2010.

[18] C.R. Bala Murugan, S.P. Natarajan, R. Bensraj, "Dspace Based Implementation of Various Inverted Sine Carrier PWM Strategies for Three Phase Five Level H-Bridge Inverter", International Journal of Advanced Engineering Technology, Vol.7, pp.103-112, March 2016.

Int J Pow Elec \& Dri Syst, Vol. 10, No. 2, June 2019: 1003 - 1013 


\section{BIOGRAPHIES OF AUTHORS}
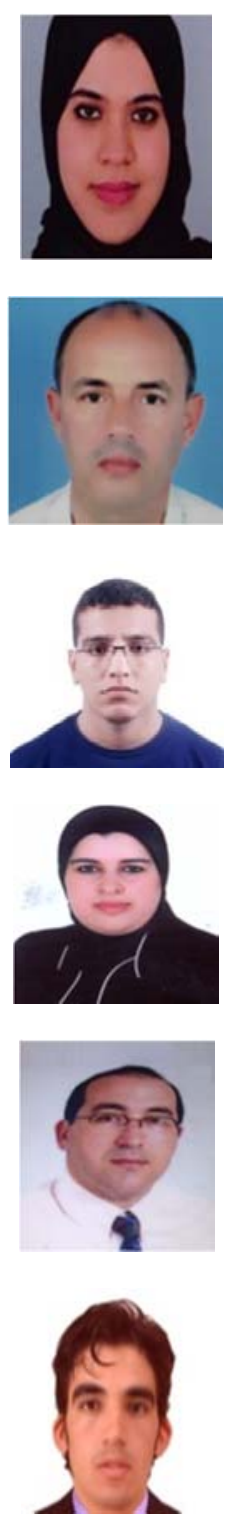

Sara Mensou was born on 1992 in Rabat, Morocco. She received the Master degree in Industrial Automation Systems Engineering from Sidi Mohamed Ben Abdellah University, Fez, in 2015. She is currently pursuing $\mathrm{PhD}$ degree in renewable energy, motor drives and power system at Electrical Engineering Research Laboratory, ENSET, Mohammed V University, Rabat, Morocco. She is main area of research includes contribution to the control of the generators applied in wind turbines and dSPACE based control systems.

Ahmed Essadki was born in Morocco. He received the PhD degree in 2000 at Mohammadia Engineering School (EMI), Rabat in 2000. From 1990 to 1993, he pursued the Master program at UQTR University, Quebec Canada, in electrical engineering. His current researches include renewable energy, motor drives and power system. Ahmed is a member of RGE Lab in research group leader. Currently, he is a Professor at the electrical engineering department of ENSET, Rabat.

Issam Minka was born in Khenifra, Morocco. He holds a Master's Degree in Science and Technology entitled Microelectronic Systems of Telecommunications and Industrial Computing at the Faculty of Science and Technology of Fez, Morocco in 2014. He is currently working on a doctoral thesis in the Electrical Engineering Department of ENSET, Mohammed V University Rabat. His research interests include renewable energy, machine control and electrical systems.

Tamou Nasser was born in Morocco. She received the $\mathrm{PhD}$ degree in 2005 and her research MS degree in 2000, all in electrical engineering from Mohammadia Engineering School (EMI), Morocco. Her current research interests include renewable energy and motor drives. She is a member of Al Jazari research group. Currently, she is a Professor at the communication networks department of ENSIAS, Mohammed V University Rabat, Morocco.

Badr Bououlid Idrissi was born in Marrakech, Morocco. He received the $\mathrm{PhD}$ degree from Polytechnic Faculty of Mons, Belgium, in 1997. In 1992 he received the Diploma of engineer's degree from National School of Mineral Industry (ENIM), Rabat. Currently, he is a professor at the Electromechanical Engineering Department of ENSAM, Moulay Ismail University of Meknes. His research interests are mainly industrial control systems and DSP based control systems.

Lahssan Ben Tarla was born in Errachidia, Morocco. He received the master's degree from Ecole Normale Supérieure de l'Enseignement Technique, Rabat, Morocco, Mohammed V University. $\mathrm{He}$ is currently preparing a $\mathrm{PhD}$ thesis in the Department of Electromechanical Engineering at ENSAM Meknès, Morocco. His research areas include Flexible Manipulator, active vibration control and model predictive control. 